\title{
Comparing two observational systems in the assessment of knee pain
}

\author{
Shannon Fuchs-Lacelle MA ${ }^{1}$, Thomas Hadjistavropoulos $\mathrm{PhD}^{1}$, Donald Sharpe $\mathrm{PhD}^{1}$, Jaime Williams $\mathrm{MA}^{1}$, \\ Ronald Martin $\mathrm{PhD}^{1}$, Diane LaChapelle $\mathrm{PhD}^{2}$
}

\begin{abstract}
S Fuchs-Lacelle, T Hadjistavropoulos, D Sharpe, J Williams, R Martin, D LaChapelle. Comparing two observational systems in the assessment of knee pain. Pain Res Manage $2003 ; 8(4): 205-211$.
\end{abstract}

OBJECTIVE: Research has demonstrated the utility of the Pain Behavior Measurement (PBM) system as a pain index. PBM involves the recording of sighing, rubbing, grimacing, guarding and bracing. A modification of this system has been proposed, focusing on the occurrence of joint flexing, rubbing, unloading the joint, guarding and rigidity, specifically for patients with knee pain. The aim of the present study was to compare the original PBM to the modified version in a sample of knee replacement patients to assess the utility of the more specialized approach. It was expected that the more discomforting physiotherapy activities (knee bending and quadriceps exercises) would result in more pain behaviours than intermediate activities (walking and standing), which, in turn, would result in more pain behaviours than reclining. The extent to which each system reflected this expected pattern was examined.

METHODS: Ninety-three seniors were observed while completing a series of structured post-knee surgery physiotherapy activities (knee bending, standing, walking, reclining and a quadriceps exercise).

RESULTS: Analyses of self-reported levels of pain were consistent with the expected pattern of pain levels in relation to the physiotherapy activities. Specific pain behaviours within each system (eg, grimacing, rigidity) occurred in a manner consistent with the expected pattern, while other behaviours (eg, rubbing the affected area) did not. CONCLUSIONS: Although there was no clear advantage for the modified system over the PBM, an optimal approach may involve combining specific behaviours from each system.

\section{La comparaison de deux systèmes d'observation pour évaluer la douleur du genou}

OBJECTIF : La recherche démontre l'utilité du système de mesure de comportement à la douleur (MCD) comme indice de la douleur. La MCD consiste à prendre note des soupirs, des frottements, des grimaces et des gestes de défense et de résistance. Une modification a été proposée à ce système, axée sur l'occurrence du pliage de l'articulation, des frottements, du dépliage de l'articulation, de la défense et de la rigidité, spécifiquement pour les patients souffrant de douleur du genou. La présente étude visait à comparer la MCD à la version modifiée auprès d'un échantillonnage de patients ayant reçu une prothèse du genou, afin d'évaluer l'utilité de la démarche spécialisée. On prévoyait que les activités de physiothérapie les plus inconfortables (le pliage du genou et les exercices des quadriceps) susciteraient plus de comportements de douleur que les activités intermédiaires (marcher et se lever) qui, à leur tour, seraient plus douloureuses que le fait de se pencher. La mesure selon laquelle chaque système reflétait ce schème prévu a été examinée.

MÉTHODOLOGIE : Quatre-vingt-treize personnes âgées ont été observées pendant qu'elles effectuaient des activités de physiothérapie après une chirurgie du genou (plier le genou, se lever, marcher, se pencher et faire des exercices des quadriceps).

RÉSULTATS : Les analyses des taux de douleur autoévalués étaient compatibles avec le schème prévu des taux de douleur reliés aux activités de physiothérapie. Des comportements précis de douleur dans chaque système (p. ex., grimace, rigidité) se produisaient de manière conforme au schème prévu, tandis que d'autres comportements (p. ex., frotter la zone touchée) ne l'étaient pas.

CONCLUSIONS : Bien que le système modifié ne comporte pas de bénéfice clair par rapport à la $\mathrm{MCD}$, une démarche optimale consisterait peutêtre à combiner des comportements précis pour chaque système.

Key Words: Behavioural assessment; Elderly; Pain

lthough the estimated prevalence of painful conditions in
seniors varies across studies, there is no question that pain
is a frequent concern among many older adults because of the
prevalence of osteoarthritis and other chronic health problems
associated with aging (1-5). According to Gauthier (3), $63 \%$
of senior women and $46 \%$ of senior men experience arthritis
and/or rheumatism. Mobily et al (6) found that $86 \%$ of their
sample of noninstitutionalized seniors reported experiencing
significant pain in the year before the interview. Cook and
Thomas (2) found that $50 \%$ of older Canadian adults experience daily pain. Moreover, $28 \%$ of the participants in the Cook and Thomas study indicated that they had significant pain at least once during the week before the survey.

Despite evidence that seniors experience pain, this pain is often underreported, underrecognized and undertreated (7). For example, seniors are less likely than younger persons to be referred to pain clinics (8). Moreover, according to Hickey (9), seniors may often be reluctant to report pain. The underreporting may be due, at least in part, to common misconceptions such as the belief that pain is an integral aspect of aging

\footnotetext{
A portion of this paper was presented at the 2003 Annual Convention of the Canadian Pain Society, Toronto, Ontario

${ }^{1}$ University of Regina, Regina, Saskatchewan; ${ }^{2}$ University of New Brunswick, Fredericton, New Brunswick

Correspondence and reprints: Dr Thomas Hadjistavropoulos, Centre on Aging and Health and Department of Psychology, University of Regina, Regina, Saskatchewan S4S 0A2. Telephone 306-585-4457, fax 306-337-2321, e-mail Thomas.Hadjistavropoulos@uregina.ca
} 
and fears regarding addictions to medications $(10,11)$. As well, patients may often believe that health professionals are too busy to listen to their pain complaints.

The problem of pain underreporting is more serious among persons with dementia. Parmelee et al (5) showed that reports of pain decrease as severity of cognitive impairment increases, even after controlling for the number of health problems. Sengstaken and King (12) found that physicians failed to detect pain in a substantial number of patients with neurological problems.

Good pain assessment is necessary for the optimal management of most pain problems. Given the subjective and private nature of pain, self-reporting is often considered to represent the 'gold standard' in pain assessment. Although self-reports of pain are important and convenient, they are limited because of susceptibility to setting and demand characteristics, as well as reporting biases (13). In most cases, observational approaches focusing on behavioural reactions to pain (eg, paralinguistic vocalizations, rubbing the affected area, facial reactions and other related signals) can be used to supplement self-reported information. Such approaches may be the only effective means of pain assessment in cases where self-reporting is unavailable because of severe cognitive impairment.

Hadjistavropoulos and Craig (14) argued that nonverbal pain behaviours are more automatic and less reliant on higher mental processes than self-reporting. As such, nonverbal pain behaviours are less likely to be affected by beliefs and attitudes, or by cognitive impairment. Several of these approaches have been found to be helpful in the assessment of pain among seniors whose cognitive functioning ranges from intact to severely impaired. In a series of studies, Hadjistavropoulos and colleagues (14-16) showed that the fine grained analysis of facial responses to pain can be a valid indicator of pain and severity of pain experienced among seniors, regardless of cognitive status.

Another observational approach that has been validated as an index of pain is the Pain Behavior Measurement (PBM) system. PBM was originally developed by Keefe and Block (17) for the assessment of patients with back pain. It has since been shown to be a valid index of pain among seniors (with and without cognitive impairments) suffering from a variety of musculoskeletal pain problems $(18,19)$. PBM involves the recording of specific pain behaviours (ie, guarding, grimacing, bracing, rubbing the affected area and sighing) while the patient undergoes a series of structured activities (eg, walking, standing, reclining).

Based on the idea that the type of painful condition is likely to influence the types of pain-related behaviours displayed, Keefe et al (20) created the Osteoarthritic Pain Behavior Measurement (OA-PBM) system, a modification of PBM specific for osteoarthritic knee pain. OA-PBM involves the observational assessment of the following pain behaviours: guarding, active rubbing, unloading the joint (ie, shifting weight from one leg to another while standing), rigidity and joint flexing. To the best of the authors' knowledge, the relative usefulness of the new system (compared with the original PBM approach) has not been systematically assessed among patients with knee pain. The purpose of the present study was to examine whether the more specific system of knee pain assessment (OA-PBM) would be more sensitive in detecting pain in seniors recovering from knee surgery than the PBM system. It was expected that discomforting physiotherapy activities (knee bending and quadriceps exercises) would result in more pain behaviours than less discomforting activities (walking and standing), which, in turn, would result in more pain behaviours than reclining. It was also expected that self-report indices of pain would show a similar pattern.

\section{METHOD}

\section{Participants}

Ninety-three inpatients (64 female) over the age of 65 who were recovering from knee surgery (arthroplasty or revised arthroplasty) participated in this study. The average age of the participants was 72.9 years (SD 7.1). The average score on the Modified Mini Mental Status Examination (3MS) (21) was 91.4 (SD 6.7), which falls within the normal range of cognitive functioning (22).

\section{Measures}

Self-report pain measures: Given that pain is a subjective experience with many dimensions (affective, sensory, motivational), three self-report measures of pain, including a numerical behavioural descriptor scale, a pain intensity descriptive scale and a coloured analogue scale, were used.

Verbal pain scale (VPS) $(23,24)$ : Behaviourally-based, numerical, descriptive pain scales have been used widely in pain research $(25-27)$ and have been found to be valid indices of pain $(25,26)$. As was done in previous research (28), the VPS used in the present study consisted of six numerical ratings: $0=$ no pain; $1=$ pain present, but can easily be ignored; 2 =pain present, cannot be ignored, but does not interfere with everyday activities; $3=$ pain present, cannot be ignored, interferes with concentration; $4=$ pain present, cannot be ignored, interferes with all tasks except taking care of basic needs (eating, toilet visits); and $5=$ pain present, cannot be ignored, rest or bedrest required.

Present pain intensity scale (PPI) (29): The modified version of the PPI $(29,30)$ consists of seven numerically ranked choices of word descriptors, including no pain, slight, mild, moderate, severe, extreme, and pain as bad as it could be. Each pain intensity descriptor has a corresponding numerical score with 'no pain'=0 and 'pain as bad as it could be' $=6$. This scale has been found to be appropriate for use with older adults $(28,31)$.

Coloured visual analogue scale (CAS) (32): The CAS was originally developed to provide a convenient clinical measure of pain for children with marginal self-reporting skills. The CAS has been found to be simpler to administer than the standard visual analogue scale. Patients move a plastic glide along a $14.5 \mathrm{~cm}$ long triangular shape varying in width and colour, from $1 \mathrm{~cm}$ wide and light pink in colour at the bottom to $3 \mathrm{~cm}$ wide and deep red in colour at the top. The extremities on the scale are marked with "no pain" at the bottom and "most pain" at the top. Patients not only have verbal cues for rating their pain severity, but also visible cues in the variations in width and changes in hue from pink to red. On the back side of the tool, there are numbers marked from zero to 10 , allowing the person administering the scale to record a number that represents the patient's self-reported pain severity. The CAS approach has been found to be reliable and valid for use with children (32), and with both cognitively intact seniors and seniors with mild to moderate cognitive impairment $(16,33)$. 


\section{Observational pain indices:}

PBM: PBM involves the coding of pain behaviours while patients engage in a series of standardized activities. While the patients are engaging in these activities, coders record occurrences of the following pain behaviours:

- "guarding - abnormally stiff, interrupted or rigid movement while moving from one position to another;

- bracing - a stationary position in which a fully extended limb supports and maintains an abnormal distribution of weight, held for at least $3 \mathrm{~s}$;

- rubbing - touching, rubbing or holding the affected area of pain for a minimum of $3 \mathrm{~s}$;

- grimacing - an obvious facial expression of pain that includes a furrowed brow, narrowed eyes, tightened lips, corners of mouth pulled back and clenched teeth; and

- sighing - an obvious exaggerated exhalation of breath, usually accompanied by shoulders first rising and then falling, and cheeks may be expanded" (17, p 366).

The validity and reliability of this system have been supported in studies of younger adults and seniors with a variety of musculoskeletal problems (17-19).

OA-PBM: represents an adaptation of the PBM system for patients with osteoarthritic knee pain. The modified system involved coding the following behaviours:

- "guarding - abnormally slow, stiff or rigid movement while shifting from one position to another or while walking;

- active rubbing - hands moving over or grabbing the affected knee(s) and the legs, palm down;

- unloading joint - shifting weight from one leg to the other while standing;

- rigidity - excessive stiffness of the affected knee(s) during activities other than walking; and

- joint-flexing - flexing of the affected knee(s) while in a static position (ie, during standing or sitting)" (20, p 311).

The validity of the OA-PBM system has been found to be satisfactory. For example, scores on the system are correlated with both the patient's self-report and the rheumatologists' ratings of pain (20).

\section{Procedure}

Videotapes: Participants were videotaped while engaging in routine postoperative physiotherapy activities. The activities included $1 \mathrm{~min}$ each of walking, a knee bending exercise, a quadriceps exercise, standing and reclining. The order in which these activities were performed was randomized for each patient. Immediately following the completion of each activity, the patients were asked to respond to the three self-report measures of pain.

Coding of videotapes: Coders identified the frequency of the various pain behaviours (as defined by the OA-PBM and PBM systems) by observing the videotapes of the patients' pain reactions. A different coder was used for each observational system.
The coders were blind with respect to the hypotheses of this study. An independent coder trained in PBM and OA-PBM viewed and coded a random selection of $30 \%$ of the participants' video segments to assess interrater reliability. The interrater agreement was excellent, with $94.7 \%$ agreement for the PBM and 97.7\% agreement for OA-PBM.

Based on descriptions of the pain behaviours provided by Keefe and Block (17) and Keefe et al (20), it was decided to code four of the pain behaviours (guarding, bracing, unloading the joint and rigidity) only during some of the structured activities and/or exercises that the patients engaged in. Because the instruction for bracing suggested that bracing should be coded when the participant was stationary and weight bearing, bracing was only coded during standing. Unloading the joint also required that the participant be stationary and weight bearing. As such, it was decided that it would be most appropriate to code it only during standing. Moreover, based on the descriptions provided by Keefe et al (20), it was decided not to code rigidity during walking. Guarding for the OA-PBM system required that the participant shift from one position to the next or walk. Therefore, OA-PBM guarding was not coded for activities other than walking. Although guarding is defined in a similar manner for both the PBM and OA-PBM systems, it was not coded for the same activities for the OA-PBM system and the PBM system. The PBM system has only one coding category (guarding) for limb movements whereas the OA-PBM had two (guarding and rigidity), which allowed for greater discrimination between limping while walking (guarding for both systems) and slow, interrupted and rigid movements while performing the quadriceps and knee bending exercises. Given the absence of the rigidity option in the PBM system, PBM guarding was coded during walking, the quadriceps exercise and the knee bending exercise.

Each coder recorded the presence or absence of each behaviour of interest within $5 \mathrm{~s}$ segments. Participants received a score of one with respect to a specific behaviour (eg, guarding) when the behaviour occurred within a $5 \mathrm{~s}$ segment. Each behaviour was coded up to one time every $5 \mathrm{~s}$. Therefore, for each minute, the maximum number of occurrences for each coded behaviour was 12 . The overall scores on each activity for the PBM and OA-PBM systems were calculated by summing the number of $5 \mathrm{~s}$ segments in which each of the coded behaviours occurred. The calculated sum for each activity was then converted into a score out of 60 to ensure comparability of the overall scores for the various behaviours.

\section{RESULTS}

Self-reports of pain and scores on the observational indices during each physiotherapy activity (walking, knee bending exercise, a quadriceps exercise, standing and reclining) were analysed using within-subjects analyses of variance (ANOVAs). Planned comparisons, using the least significant difference method, were used following the identification of significant main effects. The level of significance was set at the 0.01 level for all comparisons.

\section{Self-report}

Means and standard deviations for each of the three selfreported pain measures (broken down by activity) are presented in Table 1. The pattern of scores across activities is shown in 
TABLE 1

Mean scores on each pain assessment technique for each physiotherapy activity

\begin{tabular}{lccc}
\hline & CAS (SD) & VPS (SD) & PPI (SD) \\
\hline Reclining & $2.83(2.18)$ & $1.70(1.20)$ & $1.84(1.20)$ \\
Standing & $3.78(2.41)$ & $2.19(1.26)$ & $2.56(1.33)$ \\
Walking & $3.69(2.32)$ & $2.14(1.22)$ & $2.44(1.36)$ \\
Quadriceps exercise & $5.31(2.45)$ & $3.04(1.24)$ & $3.33(1.13)$ \\
Knee bending & $5.48(2.35)$ & $3.08(1.14)$ & $3.41(1.03)$
\end{tabular}

CAS Coloured visual analogue scale; PPI Present pain intensity scale; VPS Verbal pain scale

Figure 1. To examine the patients' self-reported pain scores for each activity, separate repeated measure ANOVAs were conducted for each of the three self-reported pain measures. A significant main effect for the CAS was found $(F[4,364]=50.67$, $\mathrm{P}<0.001)$. Planned comparisons indicated that reclining was less painful than standing $(\mathrm{t}[91]=4.43, \mathrm{P}<0.001)$. Standing was as painful as walking but less painful than the quadriceps exercise $(\mathrm{t}[91]=6.02, \mathrm{P}<0.001)$ and knee bending $(\mathrm{t}[91]=7.10$, $\mathrm{P}<0.001)$. Walking was found to be less painful than the knee bending exercise $(\mathrm{t}[91]=7.41, \mathrm{P}<0.001)$ and the quadriceps exercise $(\mathrm{t}[91]=6.82, \mathrm{P}<0.001)$. Scores on the quadriceps exercise did not differ from scores obtained during knee bending.

A significant main effect for the VPS was also found $(F[4,368]=37.81, \mathrm{P}<0.01)$. Planned comparisons indicated that reclining was less painful than standing $(\mathrm{t}[92]=3.53, \mathrm{P}<0.001)$. Standing was as painful as walking, but less painful than the quadriceps exercise $(\mathrm{t}[92]=5.91, \mathrm{P}<0.001)$ and knee bending $(\mathrm{t}[92]=6.68, \mathrm{P}<0.001)$. Walking was less painful than knee bending $(\mathrm{t}[92]=6.83, \mathrm{P}<0.001)$ and the quadriceps exercise $(\mathrm{t}[92]=6.03, \mathrm{P}<0.001)$. The quadriceps and knee bending exercises did not differ with respect to VPS scores.

Finally, a significant main effect for the PPI was found $(F[4,368]=47.55, \mathrm{P}<0.01)$. Planned comparisons demonstrated that scores for reclining were lower than for standing $(\mathrm{t}[92]=5.22, \mathrm{P}<0.001)$. Standing was as painful as walking, but less painful than the quadriceps exercise $(\mathrm{t}[92]=5.39, \mathrm{P}<0.001)$ and knee bending $(\mathrm{t}[92]=6.42, \mathrm{P}<0.001)$. Walking was less painful than knee bending $(\mathrm{t}[92]=7.06, \mathrm{P}<0.001)$ and the quadriceps exercise $(\mathrm{t}[92]=5.77, \mathrm{P}<0.001)$. The quadriceps and knee bending exercises did not differ with respect to PPI scores.

\section{PBM}

A repeated measures ANOVA with five within-subjects levels (one for each physiotherapy activity) was conducted for the overall PBM scores (Table 2). The pattern of scores across activities is shown in Figure 2. The ANOVA was significant

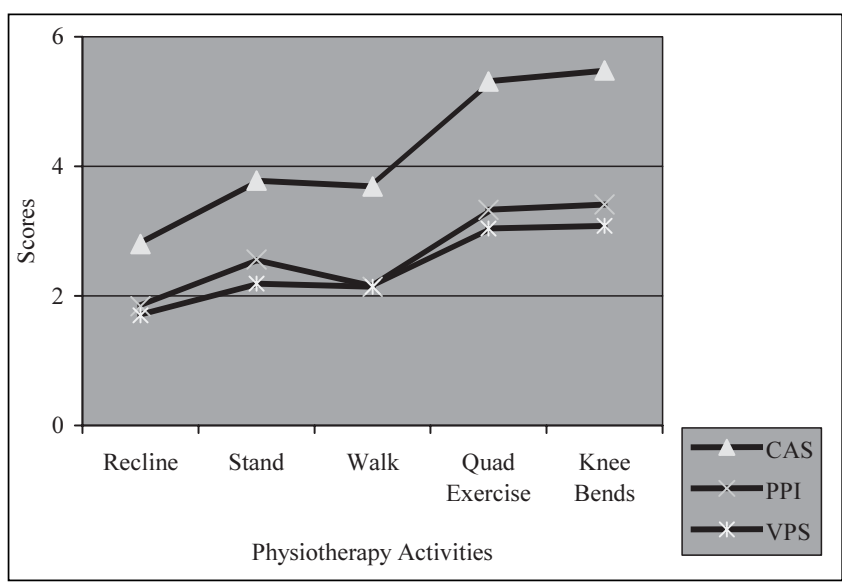

Figure 1) Scores on the verbal pain scale (VPS), present pain intensity scale (PPI), and the coloured analogue scale (CAS) across physiotherapy activities

$(\mathrm{F}[4,320]=138.23, \mathrm{P}<0.01)$. Planned comparisons demonstrated that scores for reclining were significantly lower than for standing $(t[86]=16.60, P<0.001)$. Scores for standing were significantly lower than for walking $(\mathrm{t}[83]=4.17, \mathrm{P}<0.001)$. Scores for walking did not differ from scores for the quadriceps exercises but were lower than scores for knee bending $(\mathrm{t}[80]=5.10$, $\mathrm{P}<0.001)$. Finally, scores for knee bending were higher than those for the quadriceps exercise $(\mathrm{t}[85]=2.8, \mathrm{P}<0.01)$.

Additional within-subjects ANOVAs were conducted involving each of the specific PBM behaviours (ie, bracing, guarding, grimacing, rubbing and sighing). There was no significant main effect for rubbing or bracing. The main effect for guarding was significant $(\mathrm{F}[2,170]=10.46, \mathrm{P}<0.001)$. Planned comparisons using the least significant difference method showed that guarding scores for walking did not differ from those obtained during knee bending but were significantly higher than for the quadriceps exercise $(\mathrm{t}[85]=3.89, \mathrm{P}<0.001)$. Scores for the quadriceps exercise were significantly lower than scores for knee bending $(\mathrm{t}[89]=2.79, \mathrm{P}<0.01)$.

There was also a significant main effect for sighing $(\mathrm{F}[4,344]=15.73, \mathrm{P}<0.001)$. Planned comparisons demonstrated that reclining, standing and walking did not differ from one another. However, these three scores were significantly lower than the scores obtained during the quadriceps exercise $(\mathrm{t}>3.83, \mathrm{P}<0.001)$ and knee bending $(\mathrm{t}>4.23, \mathrm{P}<0.001)$. Knee bending and quadriceps exercise scores did not differ from each other.

Finally, there was a significant main effect for grimacing $(F[4,344]=40.18, P<0.001)$. Planned comparisons showed that

\section{TABLE 2}

Mean Pain Behavior Measurement scores for each coded pain behaviour

\begin{tabular}{|c|c|c|c|c|c|c|}
\hline & Sighing (SD) & Rubbing (SD) & Grimacing (SD) & Guarding (SD) & Bracing (SD) & Overall scores (SD) \\
\hline Reclining & $1.67(5.61)$ & $0.39(3.69)$ & $14.83(20.76)$ & & & $5.51(7.75)$ \\
\hline Standing & $0.98(2.99)$ & $0.00(0.00)$ & $19.49(23.66)$ & & $55.95(13.84)$ & $19.97(6.97)$ \\
\hline Walking & $1.21(3.65)$ & $0.00(0.00)$ & $28.78(22.44)$ & $58.96(4.33)$ & & $22.17(5.79)$ \\
\hline Quadriceps exercise & $7.33(14.25)$ & $0.44(2.87)$ & $38.88(22.82)$ & $51.26(18.20)$ & & $24.23(8.75)$ \\
\hline Knee bending & $7.46(13.42)$ & $0.00(0.00)$ & $41.55(22.80)$ & $56.88(9.29)$ & & $26.47(7.61)$ \\
\hline
\end{tabular}

The empty areas indicate that these pain behaviours were not coded during the particular physiotherapy activity 
scores obtained during reclining were significantly lower than scores obtained during standing $(\mathrm{t}[88]=2.10, \mathrm{P}<0.05)$. Scores obtained during standing were significantly lower than scores obtained during walking $(\mathrm{t}[87]=3.70, \mathrm{P}<0.001)$. Scores obtained during walking were lower than scores obtained during the quadriceps exercise $(\mathrm{t}[87]=3.63, \mathrm{P}<0.001)$ and knee bending $(\mathrm{t}[86]=4.96, \mathrm{P}<0.001)$. Scores obtained during the quadriceps exercise were not different from scores obtained during knee bending.

\section{OA-PBM}

A repeated measures ANOVA was conducted for the overall OA-PBM system score (Table 3). The pattern of scores across activities is shown in Figure 2. The ANOVA was significant $(F[4,344]=79.23, P<0.001)$. Planned comparisons on the overall OA-PBM score demonstrated that scores for reclining were significantly lower than for standing $(\mathrm{t}[89]=23.99, \mathrm{P}<0.001)$. Scores for standing were significantly lower than for walking $(\mathrm{t}[87]=27.57, \mathrm{P}<0.001)$. Scores for walking were significantly higher than for the quadriceps $(\mathrm{t}[86]=3.58, \mathrm{P}<0.01)$ and knee bending $(\mathrm{t}[86]=21.73, \mathrm{P}<0.001)$ exercises. Scores on the quadriceps exercise did not differ significantly from scores obtained during knee bending.

To examine further the scores on specific OA-PBM pain behaviours, a series of repeated measures ANOVAs were conducted. Table 3 demonstrates the average pain behaviour scores on the five activities. Unloading the joint and guarding could not be analysed separately because they each are likely to occur only during one activity.

The main effect for rubbing was not significant. The main effect for rigidity was significant $(\mathrm{F}[3,267]=70.157, \mathrm{P}<0.01)$. Planned comparisons showed that scores obtained during reclining were not different from scores obtained during standing but were lower than those obtained during the quadriceps $(\mathrm{t}[89]=7.40, \mathrm{P}<0.001)$ and knee bending $(\mathrm{t}[89]=49.30$, $\mathrm{P}<0.001)$ exercises. Scores obtained during standing were near zero (with minimal variance), and as such, they were considerably lower than scores obtained during the quadriceps exercise and knee bending. Scores obtained during the quadriceps exercise did not differ significantly from scores obtained during knee bending.

The main effect for joint flexing was also significant $(F[3,267]=7.67, \mathrm{P}<0.001)$. Planned comparisons showed that scores obtained during reclining were greater than scores obtained during standing $(\mathrm{t}[89]=4.28, \mathrm{P}<0.001)$ and the knee bending exercise $(\mathrm{t}[89]=3.69, \mathrm{P}<0.001)$. Scores obtained during standing were lower than scores obtained during the quadriceps exercise $(\mathrm{t}[89]=3.27, \mathrm{P}<0.01)$ and knee bending

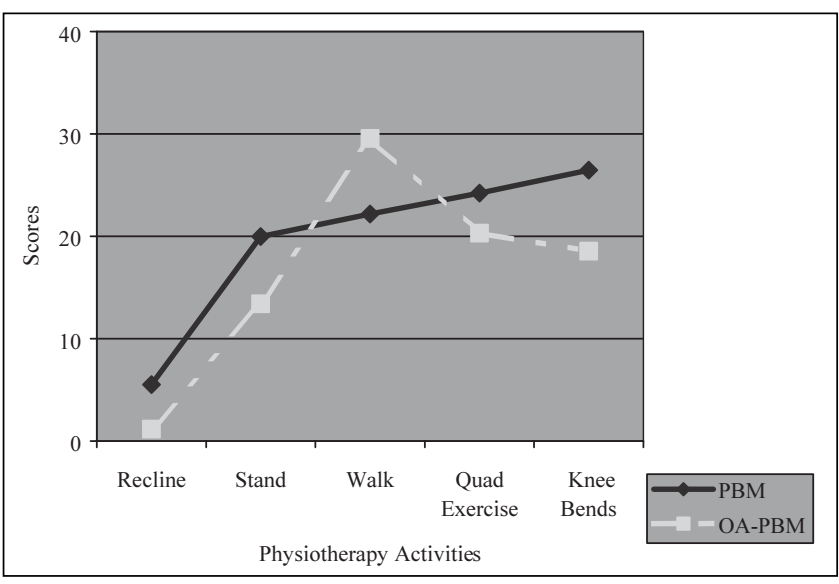

Figure 2) The overall scores for the Pain Behavior Measurement (PBM) system and the Osteoarthritic Pain Behavior Measurement (OA-PBM) system for each of the five physiotherapy activities

$(\mathrm{t}[89]=3.02, \mathrm{P}<0.01)$. Finally, scores for knee bending were lower than scores obtained during the quadriceps exercise $(\mathrm{t}[89]=3.02, \mathrm{P}<0.01)$.

\section{Relation between self-report and observational measures}

To examine the relation between self-report and the observational measures of pain, the correlations between the PBM and OA-PBM scores for each activity and each of the three selfreport measures were calculated. Sighing (PBM only) was significantly correlated with the CAS $(r[84]=0.39, \mathrm{P}<0.01)$, the PPI $(r[85]=0.37, \mathrm{P}<0.01)$ and the VPS $(r[85]=0.44, \mathrm{P}<0.01)$. No other correlations were significant.

\section{DISCUSSION}

The analyses of self-reported levels of pain in relation to physiotherapy activities were largely consistent with expectations. That is, more physically discomforting activities were associated with more self-reported pain (ie, reclining was considered to be the least painful activity, followed by walking and standing which were equally painful, and then by the quadriceps and knee bending exercises, which were also equally painful [Figure 1]). The overall scores for both the PBM system and the OA-PBM system were also generally consistent with the expected pattern (ie, more discomforting activities [walking, quadriceps exercise, knee bending] were associated with higher scores than the less discomforting activities [standing and reclining] [Figure 2]). Nonetheless, contrary to expectations, walking was rated as somewhat more painful than the quadriceps exercises

\section{TABLE 3}

Mean Osteoarthritic Pain Behavior Measurement scores for each coded pain behaviour

\begin{tabular}{|c|c|c|c|c|c|c|}
\hline & Joint flexing (SD) & Rubbing (SD) & Unloading joint (SD) & Guarding (SD) & Rigidity (SD) & Overall score (SD) \\
\hline Reclining & $3.00(6.65)$ & $0.33(3.16)$ & & & $0.17(1.17)$ & $1.17(2.43)$ \\
\hline Standing & $0.00(0.00)$ & $0.00(0.00)$ & $52.93(17.73)$ & & $0.66(6.29)$ & $13.40(4.21)$ \\
\hline Walking & & $0.00(0.00)$ & & $59.09(6.59)$ & & $29.55(3.29)$ \\
\hline Quadriceps exercise & $4.72(13.71)$ & $0.28(2.64)$ & & & $55.94(71.51)$ & $20.3(23.22)$ \\
\hline Knee bending & $0.39(1.54)$ & $0.01(0.01)$ & & & $55.22(10.60)$ & $18.55(3.37)$ \\
\hline
\end{tabular}

The empty areas indicate that these pain behaviours were not coded during the particular physiotherapy activity because they were not applicable (eg, unloading the joint does not occur during reclining) 


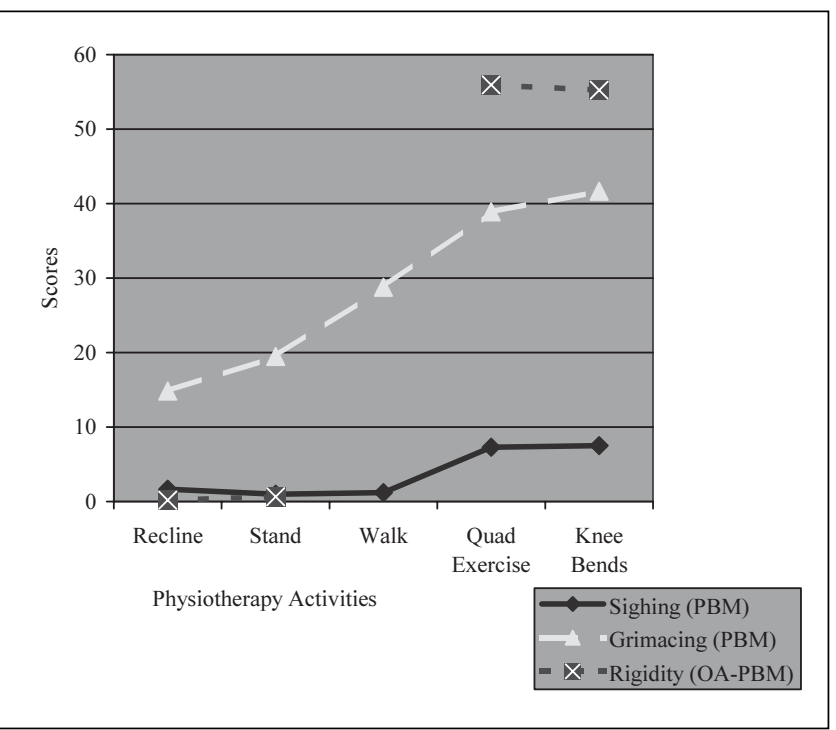

Figure 3) Average scores for sighing, guarding, grimacing and rigidity for each of the five physiotherapy activities. Guarding was only coded during the walking, the quadriceps exercise and knee bending. Rigidity was not coded during walking. OA-PBM Osteoarthritic Pain Behavior Measurement; PBM Pain Behavior Measurement

and knee bending when using the OA-PBM index. The discrepancy between the OA-PBM system and the other systems, as well as with the hypothesised expected pattern of pain, can be considered to be placing a limit on the validity of this system.

We conclude that there does not appear to be a clear advantage to using the specific pain observational system (OA-PBM) over the PBM system when working with postsurgical knee replacement patients. It appears that the pain behaviours tapped by the PBM system are pervasive enough to be useful with patients who have a variety of pain problems (not just back pain). Specific pain behaviours within each system (ie, grimacing, sighing and rigidity [Figure 3]) occurred in a manner that was generally consistent with the expected pattern, while other behaviours (eg, rubbing the affected area and joint flexing) did not. Given the inconsistent manner in which these behaviours occurred and that many did not occur very often, it may be possible to combine the most useful specific behaviours from each of the two systems (sighing, grimacing, rigidity [Figure 3]) to better evaluate pain in postoperative knee patients. This issue merits further study.

Although the overall score for our participants fell within the normal range of cognitive functioning, the behaviours used in the PBM and OA-PBM systems have great potential for application in the assessment of pain among seniors with cognitive impairments who suffer from osteoarthritis and other musculoskeletal problems. Our findings suggest, however, that clinicians interested in pain intensity may often be better off assessing patients with respect to robust pain behaviours rather than focusing on behaviours that are particular to specific kinds of pain. This being said, specific pain behaviours may be useful in identifying the location of the pain for patients who have compromised self-report capabilities because of cognitive impairment. Limping, for example, would be a possible indicator of leg pain. Rubbing a body part would be an indicator of pain in the location that is being rubbed. Other pain indicators, such as grimacing, would be very sensitive indicators that pain is occurring, but offer very limited information about the location of the pain. Research focusing on the role of nonverbal pain behaviours in helping clinicians localize pain among patients with cognitive impairments would represent a very fruitful avenue for future study.

Although scores on self-reported indices of pain were consistent with the expected pattern, they were generally not correlated with the overall PBM or OA-PBM scores for each activity. The only significant correlations involved sighing (ranging from 0.37 to 0.44 ). Several other studies failed to detect a correlation between observational pain indices and self report (34) suggesting that the two types of assessment methods tap different aspects of the pain experience and provide complementary information. As such, both types of assessment approaches should be employed when possible (34).

ACKNOWLEDGEMENTS: This study was supported by a Canadian Institutes of Health Research Investigator Award and a Saskatchewan Health Research Foundation grant to Thomas Hadjistavropoulos.

\section{REFERENCES}

1. Chiou A, Buschmann MT. The factors associated with excess disability in arthritic elderly patients. J Ment Health Aging 1999;5:151-64.

2. Cook AJ, Thomas MR. Pain and the use of health services among the elderly. J Aging Health 1994;6:155-72.

3. Gauthier P. Statistics Canada: Canada's seniors. Can Soc Trends 1997;Autumn:16-20.

4. Harkins SW. Geriatric pain: Pain perceptions in the old. Pain Manag 1996;12:435-59.

5. Parmelee PA, Smith B, Katz IR. Pain complaints and cognitive status among elderly institution residents. J Am Geriatr Soc 1993;41:517-22.

6. Mobily PR, Herr KA, Clark MK, Wallace RB. An epidemiological analysis of pain in the elderly: The Iowa $65+$ Rural Health Study. J Aging Health 1994;6:139-54.

7. Roy A, Thomas MR. A survey of chronic pain in the elderly. Can Fam Physician 1986;32:513-6.

8. Kwentus JA, Harkins SW, Lignon N, Silverman JJ. Current concepts of geriatric pain and its treatment. Geriatrics 1985;40:48-54.

9. Hickey T. Changing health perceptions of older patients and their implications for dentistry. Gerodontics 1988;4:212-6.

10. Blum RH, Simpson PK, Blum DS. Factors limiting the use of opioid analgesics for cancer pain. Am J Hosp Palliat Care 1990;7:31-5.

11. Widner S, Zeichner A. Psychologic interventions for the elderly chronic care patients. Clin Gerontol 1993;13:3-18.

12. Sengstaken E, King S. The problems of pain and its detection among geriatric nursing home residents. J Am Geriatr Soc 1993;41:541-4.

13. Craig KD. The facial expression of pain: Better than a thousand words. Am Pain Soc J 1992;1:153-62.

14. Hadjistavropoulos T, Craig KD. A theoretical framework for understanding self-report and observational measures of pain: A communications model. Behav Res Ther 2002;50:551-70.

15. Hadjistavropoulos T, Craig, KD, Martin N, Hadjistavropoulos H, McMurtry B. Toward a research outcome measure of pain in frail elderly in chronic care. Pain Clin 1997;10:71-80.

16. Hadjistavropoulos T, LaChapelle D, MacLeod F, Hale C, O'Rourke N, Craig KD. Cognitive functioning and pain reactions in hospitalized elders. Pain Res Manag 1998;3:145-51.

17. Keefe FJ, Block AR. Development of an observation method for assessing pain behaviour in chronic low back patients. Behav Ther 1982;13:363-75.

18. Hadjistavropoulos T, LaChapelle D, Macleod F, Snider B, Craig K. Measuring movement-exacerbated pain in cognitively impaired frail elders. Clin J Pain 2000;16:54-63. 
19. Weiner D, Pieper C, McConnell E, Martinez S, Keefe FJ. Pain measurement in elders with chronic low back pain: Traditional and alternative approaches. Pain 1996;67:461-7.

20. Keefe FJ, Caldwell DS, Queen K, et al. Osteoarthritic knee pain: A behavioural analysis. Pain 1987;28:309-21.

21. Teng EL, Chui HC. The modified Mini-Mental State (3MS) Examination. J Clin Psychiatry 1987;48:314-18.

22. Tombaugh TN, McIntyre NJ. The Mini-Mental State Examination: A comprehensive review. J Am Geriatr Soc 1992;40:922-35.

23. Budzynski TH, Stoyva JM, Adler CS, Mullaney DJ. EMG biofeedback and tension headache: A controlled outcome study. Psychosom Med 1973;35:484-96.

24. Linton SJ, Gotestam KG. A clinical comparison of two pain scales: Correlation, remembering chronic pain and a measure of compliance. Pain 1983;17:57-65.

25. Aydin ON, Kir E, Ozkan SB, Gursoy F. Patient-controlled analgesia and sedation with fentanyl in phacoemulsification under topical anesthesia. J Cataract Refract Surg 2002;28:1968-72.

26. Carr MP, Horton JE. Clinical evaluation and comparison of 2 topical anesthetics for pain caused by needle sticks and scaling and root planning. J Periodontol 2001;72:479-84.
27. Reuben SS, Sklar J. Intravenous regional anesthesia with clonidine in the management of complex regional pain syndrome of the knee. J Clin Anesth 2002;14:87-91.

28. Gagliese L, Melzack R. Lack of evidence for age differences in pain beliefs. Pain Res Manag 1997;2:19-28.

29. Melzack R. The McGill Pain Questionnaire: Major properties and scoring methods. Pain 1975;1:277-99.

30. Melzack R. The short-form of the McGill Pain Questionnaire. Pain 1987;30:191-7.

31. Gagliese L, Katz J. Age differences in postoperative pain are scale dependent: A comparison of measures of pain intensity and quality in younger and older surgical patients. Pain 2003;103:11-20.

32. McGrath PA, Seifert SE, Speechley KN, Booth JC, Stitt L, Gibson MC. A new analogue scale for assessing children's pain. Pain 1996;64:435-43.

33. Schreder EJ, Bouma A. Visual analogue scales for pain assessment in Alzheimer's disease. Gerontology 2000;46:47-53.

34. Labus JS, Keefe FJ, Jensen MP. Self-reports of pain intensity and direct observations of pain behavior: When are they correlated? Pain 2003;102:109-24. 


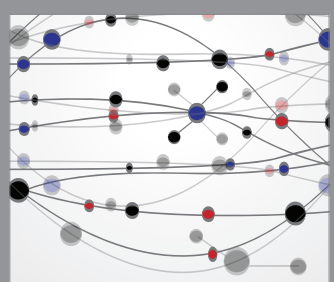

The Scientific World Journal
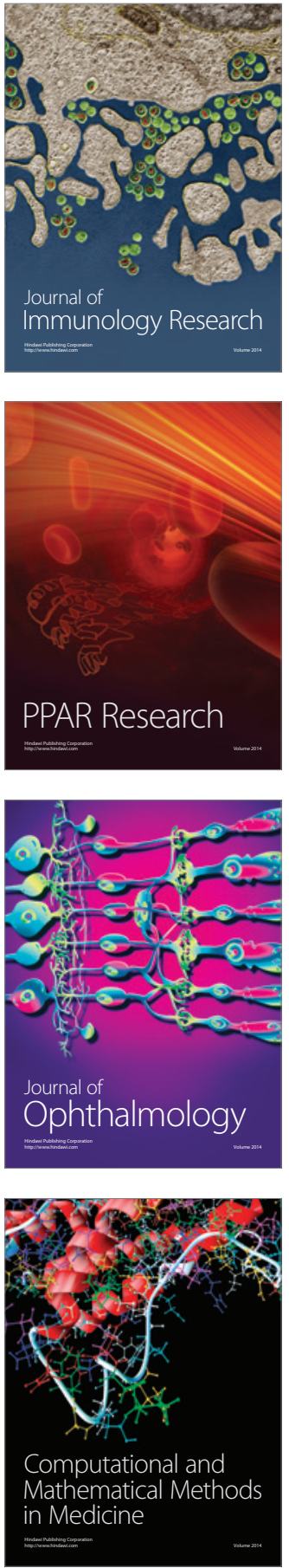

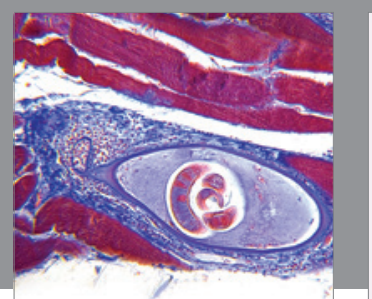

Gastroenterology Research and Practice

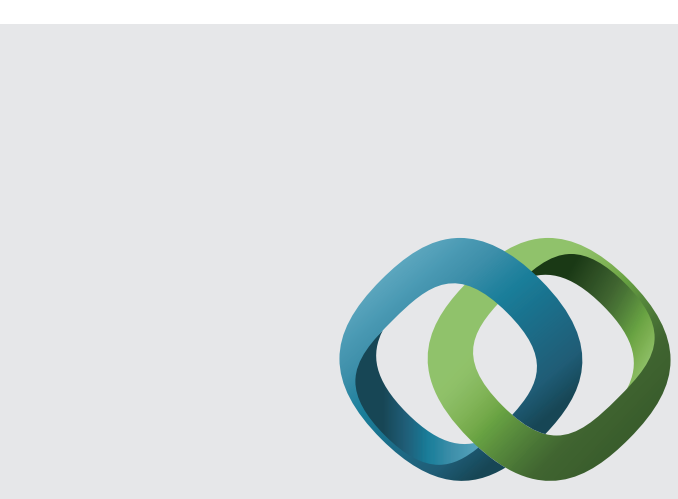

\section{Hindawi}

Submit your manuscripts at

http://www.hindawi.com
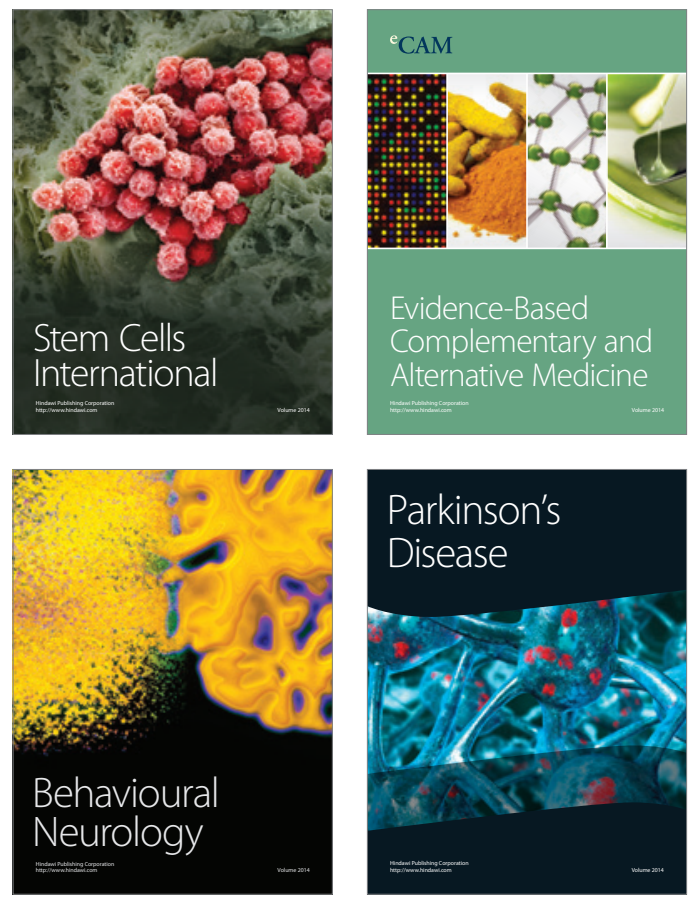
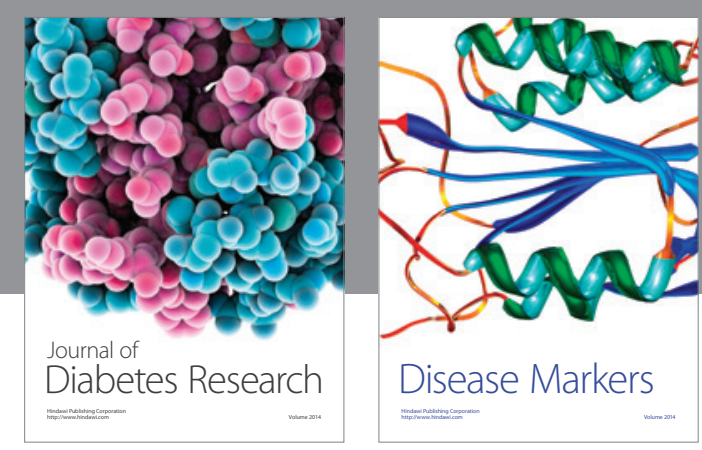

Disease Markers
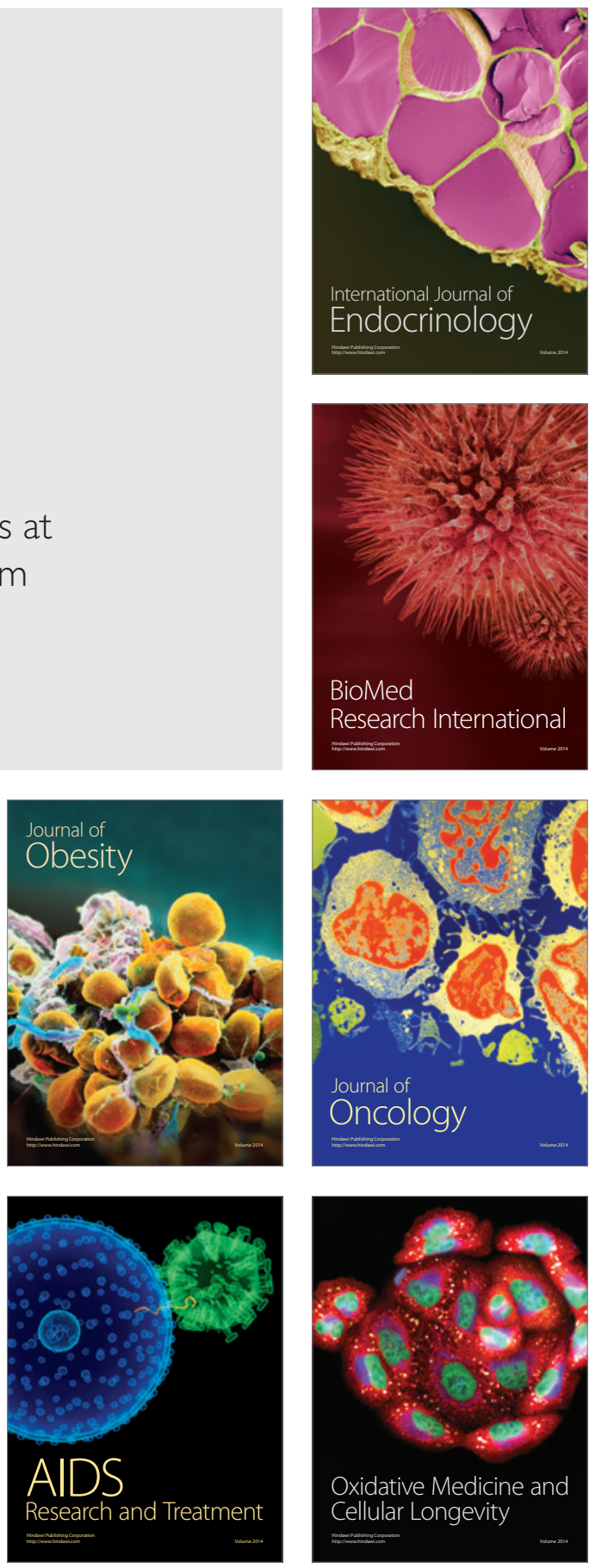